\title{
Multimodal electrophysiological studies including motor evoked potentials in patients with locked-in syndrome: report of six patients
}

\author{
Claudio Bassetti, Johannes Mathis, Christian W Hess
}

\begin{abstract}
Clinical and electrophysiological findings in six patients with locked-in syndrome are reported. Motor evoked potentials (MEPs) after magnetic stimulation of the motor cortex were absent in four patients, none of whom recovered clinically. In two patients, MEPs could be obtained from the severely paretic limbs and almost full motor recovery followed. Somatosensory evoked potentials were altered in four of the patients, and brainstem auditory evoked potentials were altered in two of four patients examined, showing a clinically unsuspected tegmental involvement. The EEG showed a predominance of reactive alpha activity in all patients, documenting a preserved consciousness. It is concluded that a multimodal electrophysiological approach, in addition to clinical assessment, can be helpful in diagnosing locked-in syndrome, estimating the extension of the underlying brainstem dysfunction, and predicting functional outcome.
\end{abstract}

(F Neurol Neurosurg Psychiatry 1994;57:1403-1406)

The term "locked-in" was coined in 1966 by Plum and Posner $^{1}$ for a condition first described by Alexandre Dumas in his book The Count of Monte Cristo. The locked-in syndrome is characterised by tetraplegia, paralysis of all cranial motor functions except vertical eye movements, and preserved consciousness that can be assessed by means of communication through a blinking code. Ventral pontine vascular lesions are the most common cause of locked-in syndrome. During the past few years, an increasing number of reports allowed the recognition of different varieties of locked-in syndrome with respect to the clinical picture (classic, incomplete, and total forms), topography of the lesion (mesencephalic and pontine lesions), aetiology (vascular and non-vascular causes), and evolution (transient and chronic forms) of the disorder. ${ }^{1-8}$

The preserved consciousness can be ascertained by a normally reactive alpha rhythm in the EEG. ${ }^{9}$ Involvement of tegmental brain- stem structures in locked-in syndrome is not uncommon and has been documented in several patients by means of somatosensory and evoked potentials (SEPs) and brainstem auditory evoked potentials (BAEPs). ${ }^{10}$ Conversely, dysfunction of the pyramidal tract has been shown electrophysiologically with the help of motor evoked potentials (MEPs) only once. ${ }^{11}$

The outcome of locked-in syndrome is generally poor. In a review of 139 cases, Patterson and Grabois ${ }^{7}$ reported a mortality of $67 \%$ in vascular and of $41 \%$ in nonvascular cases. Over the past years, however, patients with good recovery have been reported, ${ }^{36-8}$ stimulating a search for prognostic indicators. Because of the lack of knowledge about the diagnostic and prognostic value of a multimodal electrophysiological approach we decided to study six consecutive patients with locked-in syndrome by means of a systematic protocol including clinical assessment, EEG, SEPs, BAEPs, and MEPs.

Methods

Transcranial magnetic stimulation of the motor cortex and transcutaneous high voltage electrical stimulation of the cervical motor roots (for the upper limb muscles) were performed as described elsewhere. ${ }^{12}$ For magnetic stimulation a specially designed powerful magnetic stimulator with a total capacitance of $800 \mu \mathrm{F}$ and a total maximal charging energy of $2500 \mathrm{~J}$ was employed. A circular stimulating coil-mean diameter 8 $\mathrm{cm}$ and total inductance $30 \mu \mathrm{H}$-was centred over the vertex for the upper limb muscles and placed 2-4 cm anteriorly for the lower limb muscles with the current flowing anticlockwise as viewed from above (as conventionally defined) to excite the right sided muscles and vice versa. The MEPs were recorded from the abductor digiti minimi, biceps brachii, and tibialis anterior muscles of both sides from surface electrodes placed over the belly and tendon of the target muscles. Stimulus intensity was increased stepwise until reproducible responses were obtained, and three to four compound muscle action potentials (CMAPs) were recorded from each 
target muscle. Recordings were made with a four channel EMG device (Medelec sensor) with amplifier bandpass filters from $3 \mathrm{~Hz}$ to 3 $\mathrm{kHz}$. In earlier studies on normal subjects it was always possible to obtain unequivocal responses from those target muscles even without facilitation by voluntary contraction. When no response could be evoked until $100 \%$ of stimulus output strength, painful stimuli were applied to the respective limb, sufficient to induce some reaction (in the face) just before the cortical stimulus to facilitate the responses. The onset latencies of the CMAPs obtained from cortical and cervical stimulation were measured. The central motor conduction time (CMCT) to the abductor digiti minimi, biceps brachii, and tibialis anterior muscles was defined as the difference between the onset latencies after cortical and motor root stimulation.

The BAEPs were elicited by monoaural clicks with an intensity of 75-95 dB above sensory level delivered at $10 / \mathrm{s}$ while masking the contralateral ear with white noise. Recording was done with a Medelec sensor device and amplifier bandpass filters from 1 $\mathrm{Hz}$ to $1 \mathrm{kHz}$. The recording needle electrodes were placed at $\mathrm{Cz}^{\prime}$ (indifferent) and $\mathrm{A} 1 / \mathrm{A} 2$ (different) according to the 10-20 nomenclature.

The SEPs were obtained by electrical stimulation of the median nerve at the wrist with square wave pulses of $0.2 \mathrm{~ms}$ duration and an intensity of $4 \mathrm{~mA}$ above motor threshold of the thenar muscle delivered at 3 to $5 \mathrm{~Hz}$. Bipolar recordings were made with a Medelec sensor device and bandpass filters from $3 \mathrm{~Hz}$ to $3 \mathrm{kHz}$ with the recording needle electrodes placed according to the 10-20 nomenclature: (a) ipsilateral Erb's point to $\mathrm{Fz}$; b ) spinous process of $\mathrm{C} 7$ to $\mathrm{Fz} ;(c)$ contralateral handfield (P3/P4) to the ipsilateral ear (A1/A2); (d) P3/P4 to Fz. Two samples each of 512 to 1024 sweeps were averaged on either side.

The EEG recordings were taken with an eight channel machine for at least 30 minutes with both bipolar and unipolar (Wilson) reference. At the same time reaction to pain, passive eye opening, and acoustic stimuli were tested.

The results of the MEPs, BAEPs, and SEPs were compared with the normative data of our laboratory. A result was judged abnormal when it was more than $2.5 \mathrm{SD}$ beyond the mean of our normal data.

\section{Results}

The table summarises the principal clinical, radiological, and electrophysiological features of the six patients studied.

\section{CLINICAL FINDINGS}

All patients (three men and three women, age ranging from 16 to 71 years) presented with the locked-in syndrome as defined by Plum and Posner. ${ }^{1}$ Locked-in syndrome appeared after successful resuscitation after cardiac arrest in patient 4 , and after general anaesthesia for osteosynthesis in patient 5 . In the other four patients, locked-in syndrome was preceded by symptoms and signs of vertebrobasilar ischaemia. In the classification proposed by Bauer et al, ${ }^{3}$ patients 4 and 6 had a partial locked-in syndrome because of partially preserved horizontal eye movements. In the remaining patients the syndrome was complete. In all patients tetraparesis was severe. Patient 2 and 3 died within the first week after admission. Patient 1 and 5 evolved to a chronic locked-in syndrome (follow up of four years and one year respectively). Patients 4 and 6 made a good functional recovery (independent in everyday activities) within four months of onset of locked-in syndrome.

\section{NEURORADIOLOGY}

All patients had brain CT, which was considered to be normal in four. In two patients ( 5 and 6) brainstem infarction was suspected. Brain MRI was carried out in three patients $(1,5,6)$, confirming the presence of a bilateral ventral pontine infarction in all three (fig 1). Patient 6 had also had a right ventral mesencephalic infarction. Conventional angiography or MR angiography was performed in three patients and showed a basilar thrombosis in two $(1,5)$.

\section{ELECTROPHYSIOLOGY}

An EEG showed normally distributed, reactive alpha activity in all patients. In patient 5 , the EEG was reactive to photostimulation but not to pain or acoustic stimuli. Amplitude and latency of early (N20/P25) cortical responses of SEPs were altered bilaterally in four patients. The BAEPs were altered unilaterally or bilaterally in two of four patients.

In the acute stage, MEPs could be recorded in two patients $(4,6)$ both of whom recovered clinically. Of the four patients with initially absent MEPs, two died and two

Clinical, radiological and electrophysiological findings in six patients with locked-in syndrome

\begin{tabular}{|c|c|c|c|c|c|c|}
\hline$\overline{\text { Patient No }}$ & 1 & 2 & 3 & 4 & 5 & 6 \\
\hline $\begin{array}{l}\text { Age } \\
\text { Sex } \\
\text { Aetiology } \\
\text { EEG } \\
\text { SEP } \\
\text { BAEP } \\
\text { MEP } \\
\text { CT } \\
\text { MRI } \\
\text { Evolution }\end{array}$ & $\begin{array}{l}36 \\
M \\
\text { Brainstem stroke } \\
7-10 \mathrm{~Hz} \text { reactive } \\
\text { Altered bilateral } \\
\text { Altered unilateral } \\
\text { Absent } \\
\text { Normal } \\
\text { Pontine infarct } \\
\text { Chronic locked-in } \\
\text { syndrome† }\end{array}$ & $\begin{array}{l}39 \\
\text { M } \\
\text { Brainstem stroke } \\
9 \text { Hz reactive } \\
\text { Altered bilateral } \\
\text { Altered bilateral } \\
\text { Absent } \\
\text { Normal } \\
\text { ND } \\
\text { Death }\end{array}$ & $\begin{array}{l}60 \\
\text { F } \\
\text { Brainstem stroke } \\
\text { ND } \\
\text { altered bilateral } \\
\text { ND } \\
\text { Absent } \\
\text { Normal } \\
\text { ND } \\
\text { Death }\end{array}$ & $\begin{array}{l}60 \\
M \\
\text { Cardiac arrest } \\
10-12 \mathrm{~Hz} \text { reactive } \\
\text { Normal } \\
\text { ND } \\
\text { Normal } \\
\text { Normal } \\
\text { ND } \\
\text { Good recovery }\end{array}$ & $\begin{array}{l}16 \\
\text { F } \\
\text { Brainstem stroke } \\
7-10 \mathrm{~Hz} \text { reactive } \\
\text { Altered bilateral } \\
\text { Normal } \\
\text { Absent }{ }^{\star} \\
\text { Pontine infarct } \\
\text { Pontine infarct } \\
\text { Chronic locked-in } \\
\text { syndrome } \ddagger\end{array}$ & $\begin{array}{l}71 \\
\mathrm{~F} \\
\text { Brainstem stroke } \\
7-8 \mathrm{~Hz} \text { reactive } \\
\text { Normal } \\
\text { Normal } \\
\text { Abnormal } \\
\text { Mesencephallic infarct? } \\
\text { Pontine infarct } \\
\text { Good recovery }\end{array}$ \\
\hline
\end{tabular}

${ }^{\star}$ Reappeared on follow up; ffollow up of four years; $\ddagger$ follow up of one year. ND = not done. 
Figure 1 Patient 1; Sagittal $(A)$ and axial (B) $T 1$ weighted $M R I$ on day 5 in hospital showing a coil shaped gadolinium enhancing, bilateral

infarction at the basis of the pons.

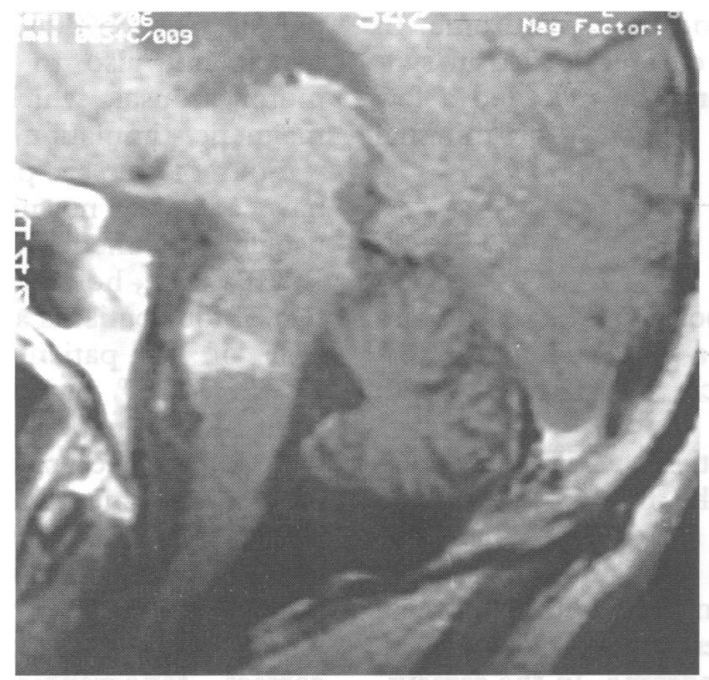

A

$\mathbf{B}$

Abductor digiti minimi
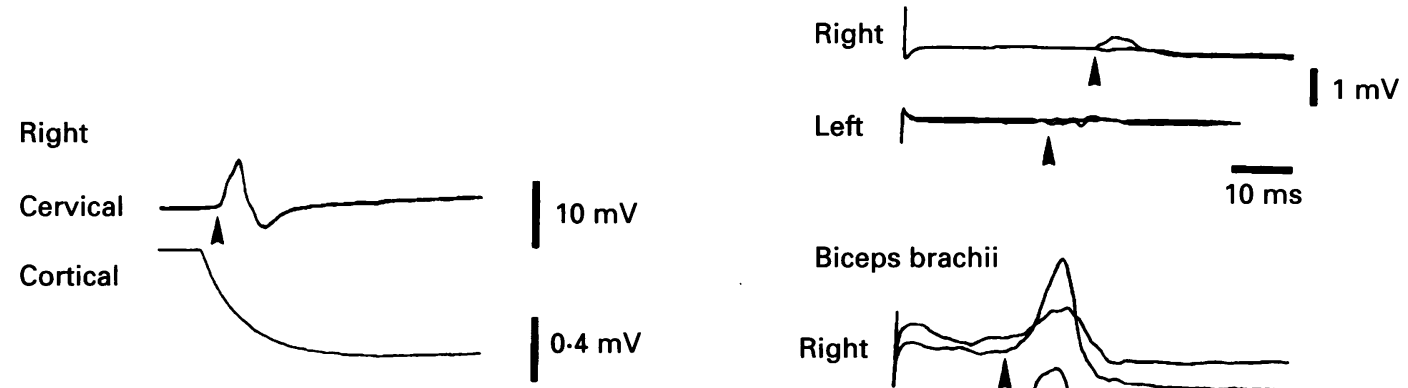

Left

Cervical

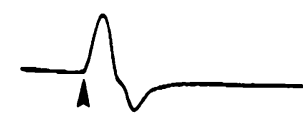

$10 \mathrm{mV}$

prolonged latency and a low amplitude (ADM right: central motor conduction time (CMCT) $20.4 \mathrm{~ms}$, amplitude 0.9 $m V(12 \%$ of amplitude obtained by stimulating at the spinal roots); $A D M$

left: CMCT $8.8 \mathrm{~ms}$

amplitude $0.3 \mathrm{mV}(4 \%)$; $B B$ right: CMCT $12 \cdot 8$ ms, amplitude $2.4 \mathrm{mV}$ (25\%); BB left: $C M C T$ $12 \cdot 8 \mathrm{~ms}$, amplitude $2 \cdot 3$ $m V(25 \%)$; TA right: corticomuscular latency ${ }^{*}$ $38.6 \mathrm{~ms}$, amplitude $3 \cdot 3$ $m V ; T A$ left:

corticomuscular latency * $36.8 \mathrm{~ms}$, amplitude $3 \cdot 3$ $m V)$. ${ }^{*}$ Stimulation of the lumbar motor roots was not done. Patient 6; MEPs after transcranial magnetic motor cortex stimulation at two days. Normal

responses were recorded from the left $A D M(C)$. Responses from the other target muscles examined (ADM right $(C)$ and both TAs (D) had a prolonged latency and reduced amplitude (ADM right: central motor conduction time (CMCT) $9.9 \mathrm{~ms}$, amplitude $0.4 \mathrm{mV}(14 \%$ of amplitude obtained by stimulating at the spinal roots); left: CMCT $7.3 \mathrm{~ms}$, amplitude $1.5 \mathrm{mV}$ (26\%); TA right: CMCT $21.1 \mathrm{~ms}$, amplitude 0.5 $m V(12 \%) ; T A$ left

CMCT $20.5 \mathrm{~ms}$

amplitude $0.2 \mathrm{mV}(6 \%))$.

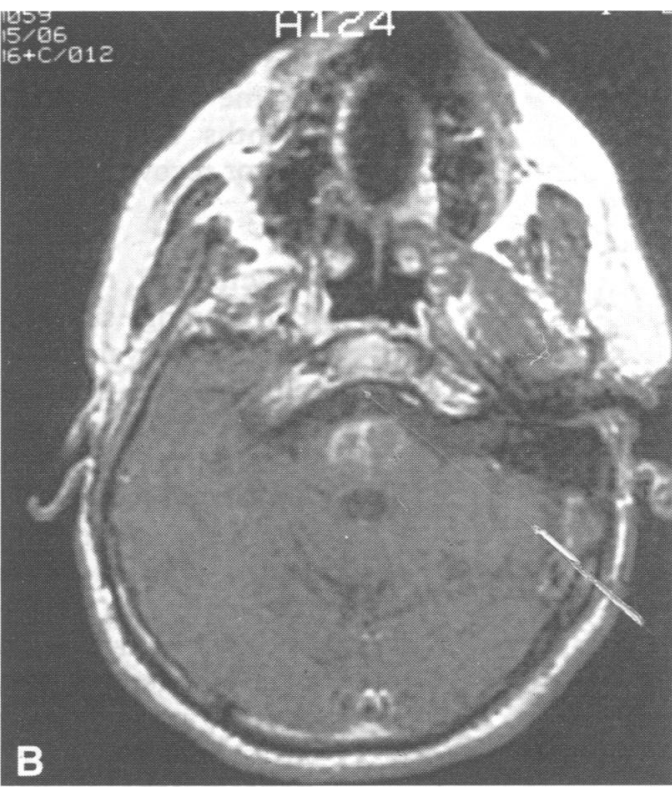

Abductor digiti minimi

$10 \mathrm{~ms}$
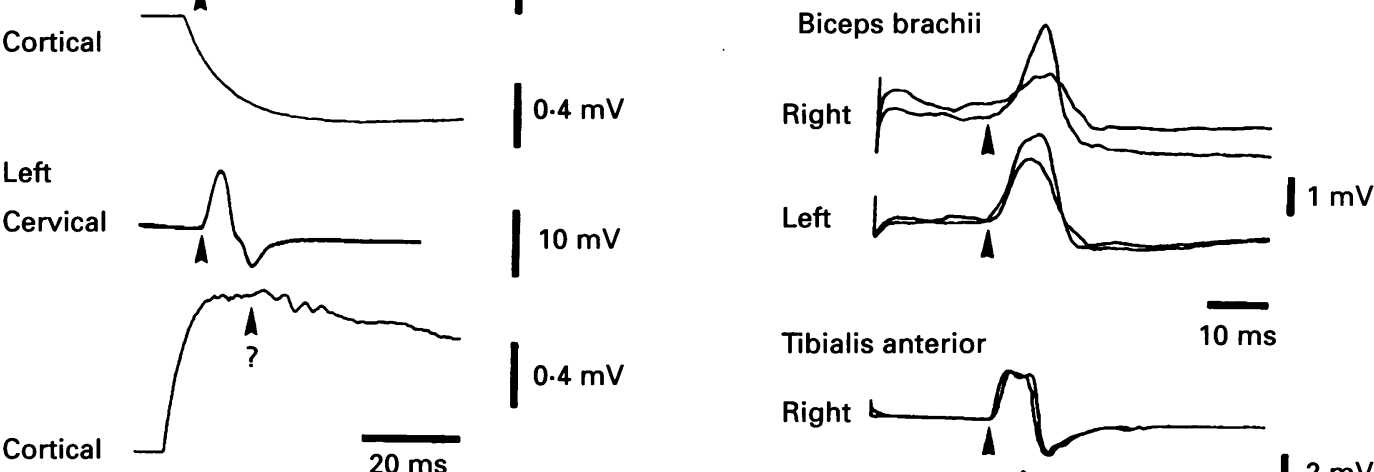

$0.4 \mathrm{mV}$

A

B

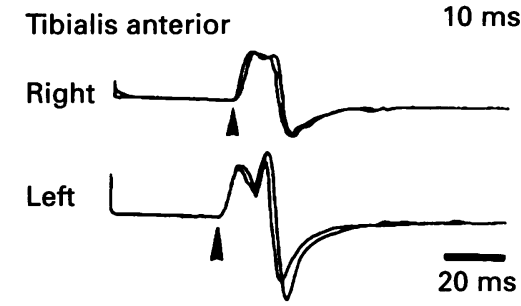

$2 \mathrm{mV}$

Tibialis anterior

Abductor digiti minimi

Right
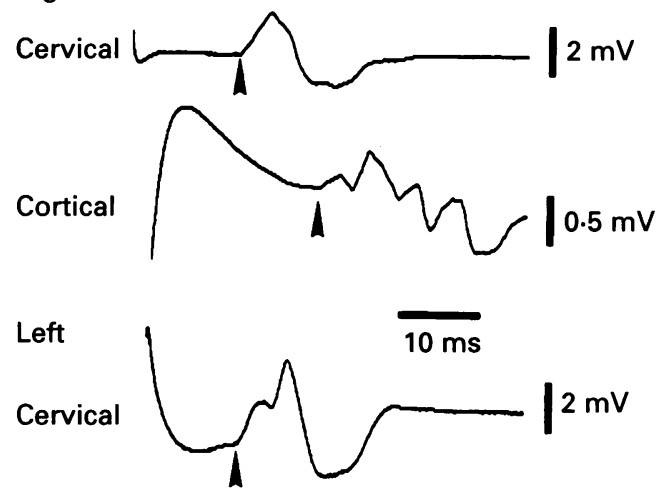

Cortical

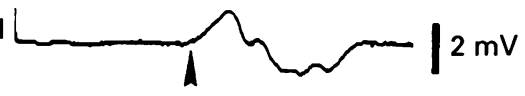

C
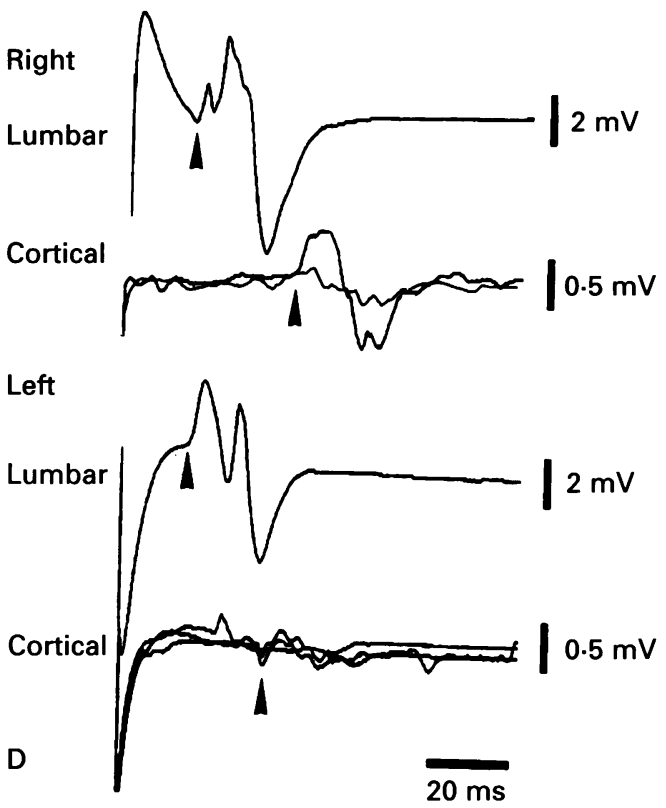
evolved to a chronic locked-in syndrome. In the two patients with chronic locked-in syndrome MEPs could only be recorded a few months later in the presence of minimal motor recovery (fig 2 ).

\section{Discussion}

Our findings suggest potential diagnostic and prognostic value for a multimodal electrophysiological approach in patients with locked-in syndrome.

In four of our six patients MEPs after magnetic stimulation of the motor cortex were abolished in the acute stage. All of them had had a pontine stroke with an unfavourable outcome: two of them died within a week, and two remained severely paretic evolving to a chronic locked-in syndrome. In the remaining two patients, who presented with lockedin syndrome after cardiac arrest and a pontomesencephalic stroke, normal or only slightly abnormal MEPs were obtained from the limbs despite nearly complete paralysis. Both of them had a favourable outcome with functionally satisfactory recovery of speech and motor functions. Thus the absence of MEPs confirmed the interruption of the pyramidal tract and heralded a poor outcome. Conversely, preservation of MEPs indicated at least partial structural integrity of corticospinal pathways and correctly suggested a potential for recovery.

The finding of preserved MEPs despite poor or absent motor functions is interesting from a neurophysiological point of view. A similar discrepancy between clinical and electrophysiological findings has been reported previously in patients with brainstem stroke ${ }^{13}$ as well as in those with traumatic spinal cord lesions. ${ }^{14}$ This could be explained on the basis of some spared corticospinal fibres, which are not accessible or too few to become effective at the motoneuron level when activated by voluntary effort as opposed to cortical stimulation. Since the work of Evarts, ${ }^{15}$ we know that spontaneous pyramidal activity in the waking monkey is continuous and regular, and increases its frequency during motion. Conversely, single cortical stimuli sufficient to excite limb muscles induce repetitive impulses in the fast pyramidal tract neurons in primates ${ }^{16}$ and in humans. ${ }^{17}$ It is thus conceivable that in our patients the strong magnetic stimuli induced abnormally long lasting bursts of impulses in the few functioning pyramidal fibres, which were sufficient to bring some motoneurons to firing level. Likewise, recovery of few pyramidal tract fibres from acute ischaemic conduction block could explain the reappearance of MEPs in the subacute stage of locked-in syndrome despite minimal clinical recovery, as also reported by Facco et al. ${ }^{11}$ Alternatively, the not uncommon presence of tegmental dysfunction evokes the possibility that clinical paresis may be due not only to an efferent deficit but also to an insufficient cortical motor arousal, which can be overcome by magnetic stimulation.

Four of our six patients were thought to have clinically normal sensory functions, as usually assumed in locked-in syndrome. ${ }^{7}$ BAEPs were, however, found to be altered in two of four patients and SEPs were altered in four of six patients examined. Similarly, Towle et $a l^{10}$ reported abnormal SEPs in eight of nine patients. These findings accord with some necropsy studies, which documented a frequent and often clinically unsuspected tegmental involvement in locked-in syndrome. ${ }^{210}$ Objective evidence of a disruption of afferent pathways in a tetraparetic patient without speech can be helpful for a correct topographic diagnosis, especially when brain CT is normal as in four of our six patients and brain MRI is not available. From a prognostic point of view, SEPs in locked-in syndrome seem less helpful than MEPs. In our experience, and in other reports, ${ }^{1011}$ normal SEPs can be followed by both a good or a bad functional recovery.

We thank $\mathrm{P}$ Huber, $\mathrm{MD}$ for performing the radiological studies and $\mathrm{K}$ Rösler, $\mathrm{MD}$ and $\mathrm{E}$ Markus, $\mathrm{MD}$ for helpful comments.

1 Plum F, Posner JB. The diagnosis of stupor and coma. 3rd ed. Philadelphia: FA Davis Co, 1980.

2 Reznick M. Neuropathology in seven cases of locked-in syndrome. $\mathcal{F}$ Neurol Sci 1983;60:67-78.

3 Bauer G, Gerstenbrand F, Rumpl E. Varieties of the locked-in syndrome. $\mathcal{F}$ Neurol 1979;221:77-91.

4 Hawkes CH. Locked-in syndrome. Report of seven cases. BMF 1974;4:379-82

5 Karp JS, Hurtig HI. "Locked-in" state with bilateral midbrain infarcts. Arch Neurol 1974;30:176-8.

6 Rae-Grant AD, Lin F, Yaeger BA, et al. Post traumatic extracranial vertebral artery dissection with locked-in syndrome: a case with MRI documentation and unusually favourable outcome. $\mathcal{F}$ Neurol Neurosurg Psychiatry 1989;52:1191-3.

7 Patterson JR, Grabois M. Locked-in syndrome: a review of 139 cases. Stroke 1986;17:758-64.

8 Yang CC, Lieberman JS, Hong CZ. Early smooth horizontal eye movements: a favourable prognostic sign in patients with locked-in syndrome. Arch Phys Med Rehabil 1989;70:230-2

9 Hawkes CH, Bryan-Smyth L. The electroencephalogram in the "locked-in" syndrome. Neurology 1974;24:101518

10 Towle VL, Maselli R, Bernstein LP, Spire JP. Electrophysiologic studies on locked-in patients: heterogeneity of findings. Electroencephalogr Clin Neurophysiol 1989;73:419-26.

11 Facco E, Caputo P, Fiore D, Giron GP. Sensorimotor and auditory central conduction time in locked-in syndrome. Electroencephalogr Clin Neurophysiol 1989;73: 552-6.

12 Hess CW, Ludin HP. Die transkranielle Kortexstimulation mit Magnetfeldimpulsen: Methodische und physiologische Grundlagen. $Z$ EEG EMG 1988;9: 209-15.

13 Ferbert A, Vielhaber S, Meincke U, Buchner $H$. Transcranial magnetic stimulation in pontine infarction: correlation to degree of paresis. $\boldsymbol{f}$ Neurol Neurosurg Psychiatry 1992;55:294-9.

14 Gianutsos J, Eberstein A, Holland T, Goodgold J. A noninvasive technique to assess completeness of spinal cord invasive technique to assess completeness of spin
lesions in humans. Exp Neurol 1987;98:34-40.

15 Evarts EV. Temporal patterns of discharge of pyramidal tract neurons during sleep and waking in the monkey. tract neurons during sleep and

16 Kernell D, Wu CP. Responses of the pyramidal tract to stimulation of the baboon's motor cortex. F Physiol (Lond) 1967;191:653-72.

17 Berardelli A, Ighilleri M, Cruccu G, Manfredo $M$. Descending volley after electrical and magnetic transcranial stimulation in man. Neurosci Lett 1990;112: $54-8$ 